\title{
EDUCAÇÃO AMBIENTAL EM LIVROS DIDÁTICOS DE CIÊNCIAS: UM ESTUDO DE REVISÃO
}

\author{
Luana Hilgert Tonin ${ }^{1}$ \\ Rosangela Inês Matos Uhmann ${ }^{2}$
}

Resumo: Esta pesquisa bibliográfica tem por objetivo analisar teses e dissertações do Instituto Brasileiro de Informação em Ciência e Tecnologia (IBICT) em atenção aos descritores: Educação Ambiental (EA) e Livros Didáticos (LD) de Ciências. Foram selecionamos quatorze pesquisas tendo como metodologia de análise as quatro concepções de EA (de Lago e Pádua (1992)), a saber: ecologia social, ecologia natural, ecologismo e conservacionismo. Observamos que doze pesquisas inclinaram-se para a concepção do conservacionismo e duas na ecologia social. Constatamos que os LD poderiam agregar mais os valores ambientais de forma crítica para que se tenha a mudança desejada: sensibilização, percepção e transformação das concepções na perspectiva da EA.

Palavras-chave: Educação Ambiental; Material Didático; Ciências.

Abstract: This bibliographic research aims to analyze theses and dissertations of the Brazilian Institute of Information in Science and Technology (IBICT) in attention to the descriptors: Environmental Education and Didactic Books of Sciences. Fourteen researches were selected using the four conceptions of Environmental Education (Lago and Pádua (1992)) as methodology of analysis, namely: social ecology, natural ecology, ecology and conservationism. We observed that twelve research studies were focused on the concept of conservationism and two on social ecology. We found that Didactic Books could add more environmental values in a critical way to achieve the desired change: awareness, perception and transformation of conceptions from the perspective of Environmental Education.

Key words: Environmental Education; Courseware; Sciences.

\footnotetext{
1 Universidade Federal da Fronteira Sul, Cerro Largo, RS. E-mail: toninhluana@gmail.com. Link para o Lattes: http://lattes.cnpq.br/1239776028423486

2 Universidade Federal da Fronteira Sul, Cerro Largo, RS. E-mail: rosangela.uhmann@uffs.edu.br Link para o Lattes: http://lattes.cnpq.br/4842408797839388
} 


\section{Introdução}

Questões relacionadas à Educação Ambiental (EA) se tornaram destaque mundial durante a década de 70 (MININNI, 2000). Um período marcado por manifestações sociais, que incluía liberação feminina e revolução estudantil. Buscaram-se, na época, direitos à liberdade, ao trabalho, à educação, à saúde, ao lazer e à participação dos cidadãos na sociedade. Concomitante a isso, no plano econômico, se fortalecia o movimento neoliberal. Em consequência disso, a industrialização passou a utilizar os recursos naturais e humanos de forma desenfreada, sendo responsável por muitos dos impactos ambientais.

Dentro desse contexto, surge a necessidade de introduzir reformas democráticas no Estado que visassem controlar os efeitos dominantes e os impactos ambientais (GROSSI, 2004). As mudanças também ocorreram na área da educação por meio de críticas aos currículos tradicionais e tecnicistas, que tinham o objetivo de formar pessoas para o mercado de trabalho. A Carta de Belgrado de 1975 já preconizava um "novo" e "produtivo" relacionamento entre estudantes e professores, entre a escola e a comunidade e entre 0 sistema educacional e a sociedade. $O$ documento censurava 0 desenvolvimento de uma nação à custa de outra e acentuava a vantagem de formas de desenvolvimento que beneficiassem a toda humanidade (MININNI, 2000 apud GROSSI, 2004). A EA também foi destaque na Conferência de Tbilisi, em 1977, com inúmeros objetivos, dentre eles, pressupostos da educação para contribuir na resolução dos problemas ambientais (MININNI, 2000).

Para Leff (2001), a EA se fortalece na construção de novos métodos interdisciplinares, questionamentos dos paradigmas dominantes, formação de professores e incorporação do saber ambiental no currículo escolar. O que requer mais observação nos materiais didáticos usados em sala de aula, a exemplo do Livro Didático (LD), aqui em especial do ensino de Ciências, pois, o mesmo assume um papel de grande importância, além de ser um dos principais materiais norteadores do trabalho docente, ele pode auxiliar na implementação da EA no âmbito formal. Ainda mais, por se transformar em um promotor da transversalidade de um tema tão complexo como a EA, uma questão problematizadora, crítica e transformadora, preocupada em manter relações com as questões sociais, culturais, éticas e ideológicas (MARPICA; LOGAREZZI, 2010).

A importância se deve ainda, segundo Fracalanza (1992), o fato de serem os LD, os materiais que mais se aproximam, ao mesmo tempo do ensino. Segundo a autora: "[...] são eles também os materiais de divulgação do conhecimento que, de forma mais generalizada, estão acessíveis aos alunos e, quiçá, aos professores" (p. 65).

Lajolo (1996), já apontavam a importância do LD, por este, atingir um público expressivo do ponto de vista quantitativo e em processo de formação. Além da importância pedagógica, o LD também é destaque por seu aspecto 
político e cultural. Isso porque, representa e reproduz os valores em relação a uma dada visão da ciência, história, interpretação dos fatos e dos conhecimentos.

No entanto, ao se utilizar o LD como instrumento pedagógico, é necessário, acima de tudo, fazer uma escolha baseada em uma análise crítica do conteúdo. Do contrário, o professor pode se tornar uma vítima, ou seja, mero reprodutor do que está contido no mesmo. Segundo Güllich (2013, p.317): "o professor que faz uso do livro didático é adotado por ele, e não o inverso, pois é aprisionado, torna-se mais um 'telespectador' passivo, quando reproduz tacitamente o conteúdo presente no livro, sem fazer uma análise crítica deste material".

Ao analisar o LD de Ciências no Brasil, destacamos a construção que envolveu inúmeros fatores, como: produção acadêmica, cursos, eventos e consultorias. Porém, da década de 1990, conforme pesquisa realizada por Amaral (2006), os LD de ciências apresentavam questões comprometedoras no quesito meio ambiente, ou seja, antropocentrismo e cientificismo exagerados, noções que se mostravam desarticuladas no tempo e no espaço sobre o ambiente. Segundo Leis e D'Amato (1995), uma radical oposição ao antropocentrismo é encontrada no biocentrismo, onde a natureza assume papel central e de destaque, não sendo mais vista como um objeto, mas sim, como sujeito.

Diante desse contexto, esta pesquisa teve por objetivo analisar em teses e dissertações no site do Instituto Brasileiro de Informação em Ciência e Tecnologia (IBICT) a questão da EA e LD de Ciências. A seguir a metodologia e, na sequência as duas categorias originadas deste estudo.

\section{Metodologia}

Esta investigação se desenvolveu dentro de uma abordagem qualitativa (LÜDKE; ANDRÉ, 1986), por meio de uma revisão bibliográfica em trabalhos acadêmicos brasileiros (teses e dissertações) disponíveis no site do IBICT, em atenção aos descritores: "Educação Ambiental e Livros Didáticos de Ciências" nos títulos, resumos e/ou palavras-chave sem a determinação do período (sendo que a pesquisa foi realizada em Julho de 2019). Segundo Santos (2006, p. 1), essa metodologia: "[...] tem papel fundamental no trabalho acadêmico, pois é através dela que você situa seu trabalho dentro da grande área de pesquisa da qual faz parte, contextualizando-o".

Dentro desse contexto, foram analisados no respectivo IBICT, trabalhos acadêmicos sobre a EA e os LD de Ciências identificados no Quadro 1, no qual constam o título e o ano de publicação. Para uma melhor compreensão, os excertos das pesquisas são apresentados em itálico, denominados de EA1, EA2... EA14, sendo que a referência completa consta no final desta pesquisa. 
Quadro 1: Trabalhos acadêmicos analisados na pesquisa.

\begin{tabular}{|c|c|c|}
\hline Pesquisa & Título & Ano \\
\hline EA1 & $\begin{array}{l}\text { Educação Ambiental: a temática da flora, da fauna e dos } \\
\text { ambientes naturais (expressões da biodiversidade) a partir da } \\
\text { educação formal. }\end{array}$ & 1998 \\
\hline EA2 & Educação Ambiental e o livro didático no ensino fundamental. & 2004 \\
\hline EA3 & $\begin{array}{l}\text { Abordagem ambiental em livros didáticos de ciências de } 1^{\underline{a}} \text { a } \\
8^{\text {a }} \text { série em } 1983 \text { e } 2008 \text { :um estudo comparativo. }\end{array}$ & 2008 \\
\hline EA4 & $\begin{array}{l}\text { O tema água em livros didáticos de ciências de primeira à } \\
\text { quarta séries do ensino fundamental. }\end{array}$ & 2008 \\
\hline EA5 & $\begin{array}{l}\text { As questões ambientais nos livros didáticos de diferentes } \\
\text { disciplinas da quinta-série do ensino fundamental. }\end{array}$ & 2008 \\
\hline EA6 & $\begin{array}{l}\text { A abordagem das questões ambientais como forma de } \\
\text { inserção da Educação Ambiental no ensino de ciências. }\end{array}$ & 2010 \\
\hline EA7 & $\begin{array}{l}\text { Meio ambiente e ética: entrecruzando olhares no ensino de } \\
\text { ciências. }\end{array}$ & 2010 \\
\hline EA8 & $\begin{array}{l}\text { As abordagens do tema meio ambiente pelos livros didáticos } \\
\text { e professores da quinta série do ensino fundamental. }\end{array}$ & 2011 \\
\hline EA9 & $\begin{array}{l}\text { Educação Ambiental e água: concepções e práticas } \\
\text { educativas em escolas municipais. }\end{array}$ & 2012 \\
\hline EA10 & $\begin{array}{l}\text { A cigarra e a formiga: a Educação Ambiental e o ensino de } \\
\text { ciências em escolas públicas de Brasília - Distrito Federal. }\end{array}$ & 2012 \\
\hline EA11 & $\begin{array}{l}\text { A metacognição no livro didático de ciências: um olhar sobre } \\
\text { a abordagem ambiental do conteúdo água. }\end{array}$ & 2016 \\
\hline EA12 & $\begin{array}{l}\text { A prática da Educação Ambiental: caso da unidade de ensino } \\
\text { Lígia Chaves Cabral no município de Lauro Müller/SC. }\end{array}$ & 2016 \\
\hline EA13 & $\begin{array}{l}\text { O tema mudanças climáticas nos livros didáticos de ciências } \\
\text { da natureza para o ensino fundamental II: um estudo a partir } \\
\text { do PNLD } 2014 \text {. }\end{array}$ & 2016 \\
\hline EA14 & $\begin{array}{l}\text { Educação Ambiental e resíduos sólidos: um estudo nas } \\
\text { escolas públicas municipais de São Paulo. }\end{array}$ & 2018 \\
\hline
\end{tabular}

Fonte: autoria própria.

Os quatorze trabalhos acadêmicos selecionados, foram analisados conforme cada uma das concepções de EA descritas por Lago e Pádua (1992) como metodologia de análise. Para tanto, as quatro concepções são: Ecologia Natural, que procura entender as leis que regem a dinâmica da vida na natureza por meio do funcionamento dos ecossistemas, não levando em consideração os impactos ambientais causados pela relação homem-natureza. Atribuem conceitos mais científicos da Ecologia. A Ecologia Social, diferentemente da anterior, mantem uma relação homem-natureza, na qual leva em consideração a ação humana como causadora de inúmeros impactos ambientais. A mesma possui uma postura mais crítica dos conteúdos, abordando, além de conceitos científicos, os problemas ambientais e 0 
desenvolvimento sustentável. Já o Conservacionismo visa a preservação tanto de áreas já degradadas pela ação humana, quanto aquelas que ainda se mantem intactas, ocorrida devido a uma relação desarmônica entre homem e natureza, pela incompatibilidade entre desenvolvimento e preservação. Por fim, a concepção Ecologismo, que aborda questões que visam mudanças econômicas, culturais e da maneira dos homens se relacionarem entre si e com a natureza. É uma concepção que visa à transformação social por meio de ações políticas, mobilização social, projetos e fontes alternativas de energia, por exemplo.

Após a análise dos dados, os mesmos foram agrupados em duas categorias, pois segundo Ludke e André (1986): "[...] as categorias devem antes de tudo refletir os propósitos da pesquisa, ter homogeneidade interna, heterogeneidade externa, inclusividade, coerência e plausabilidade". Segundo as autoras, o processo de criação das categorias surge após inúmeras leituras e releituras, onde o pesquisador detecta temas e temáticas que aparecem com mais frequência no texto.

Para tanto, as categorias são: "As Pesquisas e a questão da Educação Ambiental" e "Pesquisas e as Concepções de Educação Ambiental".

\section{As pesquisas e a questão da Educação Ambiental}

Em atenção às pesquisas, verificamos que EA1 teve por objetivo a observação e interpretação de ilustrações sobre fauna e flora em LD de Ciências, enquanto EA4 aborda conhecimentos e conceitos sobre a água, enquanto a pesquisa EA8 chama atenção para as concepções de meio ambiente por parte de alunos e professores. Já a pesquisa EA7 leva em consideração a relação homem-natureza, por meio do entendimento sobre o Meio Ambiente como relação dos seres vivos entre si e com o ambiente, concepção de Meio Ambiente, sustentabilidade e compromisso com a ética em questões ambientais.

EA6 (p.73) retrata: "As inserções das questões ambientais ainda denotam a falta de contextualização dos assuntos abordados. Os tratados em maior profundidade, representando conteúdos explorados com explicações, remetem a contextos globais. As questões de relevância local ficam restritas a exemplos, impossibilitando discussões e reflexões que envolvam situações próximas à vida dos alunos".

A pesquisa EA12 usa, como proposta metodológica, compreender atividades de conscientização nos conteúdos abordados nos materiais didáticos. Segundo a pesquisa, "O futuro de nosso planeta depende de nossas ações, as quais perpassam pela ética, pela sensibilização e, por fim, pela consciência. Nesse sentido, discutir conceitos como conscientização ou sensibilização para que sejam internalizados e disseminados por meio da Educação Ambiental (EA), com ações pedagógicas inovadoras, poderá 
construir uma sociedade que valorize e respeite o meio ambiente em que se vive" (EA12, p. 11).

No entanto, assim como a pesquisa EA6, EA12 (p.84) mostrou em seus resultados que em: "[...] relação aos conteúdos apresentados no livro didático, faltam textos que possibilitem trabalhar uma abordagem regional que incentive a compreensão da realidade local. Trabalhar questões ambientais em nível regional e local transporta a EA para o cenário escolar".

Observamos que as pesquisas EA6 e EA12 remetem ao contexto local, porém sabemos da dificuldade para isso acontecer de fato. O que exige do professor ir em busca de novas metodologias e recursos que possam envolver os alunos em tais questões, visto que no recurso do LD é impossível abordar a realidade de cada local do nosso amplo Brasil.

As pesquisas EA13 e EA14 abordam o LD, bem como a metodologia que analisam questões sobre como a EA é trabalhada a partir de problemas como as mudanças climáticas (EA13) e o problema dos resíduos sólidos na natureza (EA14). Enquanto a pesquisa EA13 trata das questões ambientais que remetem aos problemas das mudanças climáticas trabalhadas na maioria dos LD. Neste sentido: "O fato de esse tipo de assunto estar presente efetivamente nos livros didáticos é um aspecto positivo, porém, não devemos abrir mão da necessidade da abordagem desses assuntos levando em conta as complexidades inerentes aos fenômenos, pois não podemos olhar o mundo de forma simplificada, mas sim, levar todas as suas inter-relações" (EA13, p. 146).

Diante do exposto, urge contextualizar mais a prática educativa, para além de solucionar problemas de ordem física do ambiente, visto ser incapaz de discutir questões socais e princípios básicos da educação. Segundo Loureiro (2003), isso é reflexo da falta de percepção da EA como processo educativo.

A pesquisa EA14, ao analisar o problema dos resíduos sólidos na natureza, vê a importância de: "[...] ir além do monodimensional e do disciplinar, do imediatismo economicista, do individualismo e da competitividade que impossibilitam a vida coletiva e a esfera pública, do objetivismo pragmatista que ignora e exclui o plano das subjetividades" (EA14, p.199). Para tanto: "A EA necessita constituir-se num processo efetivo de desenvolvimento humano e social, principalmente na escola" (UHMANN, 2013, p. 155).

Sem desprezar as ações individuais, precisamos nos preocupar com as ações coletivas, para podermos pensar nos desafios de tornar a sociedade mais sustentável. Para isso precisamos de estratégias que visem à democratização e modificação da estrutura social vigente e voltada para a consolidação de nova relação sociedade-natureza (LOUREIRO, 2000).

Levando em consideração de que a EA precisa ser trabalhada de forma interdisciplinar e que os LD precisam passam por criteriosas análises, a pesquisa EA7 se preocupou em analisar os valores éticos e estéticos e como os temas transversais Meio Ambiente e Ética são abordados nos LD em 
diferentes disciplinas. Segundo EA7 (p.103): “Ambos estão distantes de serem desenvolvidos de forma efetiva, porque as escolas têm uma organização que dificulta a transversalidade e profissionais que precisam de melhor qualificação continuada. [...] $A$ análise dos demais documentos permitiu inferir que os conteúdos relacionados à Ética nos $P C N$ da mesma forma que os relacionados ao tema Meio Ambiente estão presentes de maneira incipiente na Escola".

Loureiro (2003) afirma que uma educação transformadora depende de ações conscientes com valores éticos e que forneçam as condições necessárias para ações modificadoras e simultâneas dos indivíduos e grupos sociais. Para tanto, precisamos trabalhar "[...] a partir da realidade cotidiana visando a superação das relações de dominação e de exclusão que caracterizam e definem a sociedade contemporânea" (LOUREIRO, 2003, p.6). Segundo o autor (2012, p. 15).

[...] a constituição do ambiente como bem comum, a produção de condições dignas para todas as pessoas sem destruir a base natural e o respeito a diversidade cultural, pressupostos para uma sociedade sustentável, se dão por meio de movimentos sociais e ações coletivas e cotidianas, pelos quais formamos nossas individualidades, que objetivam rupturas com os padrões atuais de sociabilidade. E é nesse processo, em sua unidade complexa, que se pode apreender a relevância, sim, mas não somente, da ética, da ciência, da tecnologia e do comportamento individual.

A partir desse contexto, percebemos a importância de trabalhar a interdisciplinaridade da temática ambiental, pois a mesma acaba envolvendo o mundo natural e social, onde várias áreas precisam interagir para contribuir amenizando os problemas ambientais (GONÇALVES, 2019).

\section{Pesquisas e as concepções de Educação Ambiental}

Das pesquisas verificadas, quatorze (14) foi selecionado, onde duas (2) são teses (EA2 e EA10) e as demais doze (12) são dissertações. Percebemos também, que oito (8) pesquisas foram realizadas na região Sudeste, três (3) na região Sul, uma (1) na região Norte, uma (1) no Centro Oeste e uma (1) na região Nordeste. Após leitura criteriosa feita nos trabalhos acadêmicos, caracterizamos os mesmos nas concepções de Lago e Pádua (1989) conforme Quadro 2.

Quadro 2: Pesquisas e as respectivas concepções.

\begin{tabular}{|l|c|}
\hline \multicolumn{1}{|c|}{ Identificação da pesquisa } & Concepção \\
\hline $\mathrm{EA1}, \mathrm{EA} 2, \mathrm{EA} 3, \mathrm{EA} 4, \mathrm{EA} 5, \mathrm{EA} 6, \mathrm{EA} 7, \mathrm{EA} 8, \mathrm{EA10}, \mathrm{EA12}, \mathrm{EA13}, \mathrm{EA14}$ & Conservacionismo \\
\hline EA9, EA11 & Ecologia Social \\
\hline
\end{tabular}

Fonte: os autores. 
Dentre as quatorze (14) pesquisas, oito (8) abordam como a EA é trabalhada nos LD. As demais dão ênfase a assuntos relacionados à temática ambiental, como por exemplo: água, mudanças climáticas, resíduos sólidos, ética e meio ambiente. Quanto ao tipo de pesquisa, oito (8) trabalhos realizaram pesquisa documental, quatro (4) utilizaram a pesquisa do tipo estudo de caso, uma pesquisa utilizou entrevista e outra realizou tanto a entrevista quanto o questionário para obtenção dos dados.

Após a análise da maioria das pesquisas, observamos que a EA ainda é vista como uma questão ambientalista e mercadológica, em que o meio ambiente é obtido apenas como um recurso útil ao ser humano. Portanto, podemos classificar a concepção do Conservacionismo como majoritária, aparecendo em doze (12) pesquisas. Cabe ressaltar que as concepções de Ecologia Natural e Ecologismo não foram encontradas. A concepção do Conservacionismo considera os impactos causados pelas atividades humanas, levando alguns grupos a lutarem pela conservação dos ambientes devido a sua importância para o bem-estar e sobrevivência da espécie humana.

Sorrentino (1995) aponta que esses pensamentos conservacionistas ganharam impulso nos países desenvolvidos, a partir de movimentos ambientalistas. Segundo o autor, esse movimento se configura como um ensino tradicional, onde se percebe a simples transmissão do conhecimento, onde o aluno é apenas um ser passivo, recebedor de informações.

O Conservacionismo, em momento algum apresenta projetos alternativos para transformação social. Apenas criticam os aspectos sócioeconômicos que possuem impacto destrutivo direto sobre a natureza (LAGO; PÁDUA, 1992). A pesquisa EA3, que comparou abordagens da EA no período de 1983 a 2008, "[...] constatou que predomina ainda, na maioria das coleções de livros didáticos de Ciências, a postura utilitarista e antropocêntrica da natureza e seus recursos; desconsiderando a finitude dos mesmos, motivo pelo qual devam ser utilizados e explorados com parcimônia e prudência" (p. 123).

A pesquisa EA5 traz um exemplo contido em um dos LD analisados mostrando a relação homem-natureza a respeito da visão utilitarista dos recursos naturais. Ao analisar o tema: "Rochas" no LD, a pesquisa identifica apenas conceitos dos diferentes tipos de rochas, ressaltando sua concepção e uso pelo ser humano. Além dos excertos, havia, ainda, imagens que ilustravam objetos feitos por vários tipos de rochas e que foram utilizados pelo ser humano. Outro exemplo citado, diz respeito a falta de incentivo para que os alunos, ao estudar o conteúdo proposto pelo LD, discutam e expressem suas ideias sobre possíveis soluções de impactos ambientais.

$O$ excerto da pesquisa EA5 diz respeito ao efeito estufa, onde o LD ressalta que os níveis de gases causadores do mesmo aumentam devido à atividade industrial. Ou seja: "[...] o desenvolvimento industrial é causador do mesmo, pois libera gás carbônico na atmosfera que eleva a temperatura da Terra, levando os gelos dos polos derreter e os níveis dos mares e dos 
oceanos se elevarem, e assim muitas cidades ficariam submersas. [...] é um problema que a ciência pode ajudar a resolver! (EA5, p. 108).

$\mathrm{Na}$ pesquisa EA5, o LD descreve o problema ambiental, porém não mostra soluções, ou melhor, não traz como a ciência pode resolver o problema do aumento do efeito estufa no Planeta. Atualmente, os problemas são até mais complexos, no entanto, muitos LD vêm com o mesmo tema ano após ano. Desse modo, a pesquisa realizada pela autora mostra, mais uma vez, a visão utilitarista e conservacionista do meio ambiente por parte do ser humano. Para Grün (2001, p.46): "[...] toda a estrutura conceitual do currículo e, mais especificamente o livro-texto, inocentemente continuam a sugerir que seres humanos é a referência única e exclusiva para tudo mais que existe no mundo".

$\mathrm{Na}$ pesquisa EA14 são discutidas questões referentes ao consumo e geração de resíduos e práticas de orientação quanto à separação para coleta seletiva. Porém, em nenhum momento se faz crítica sobre o que se produz ou consome, por que, como e quais os custos socioambientais. Loureiro (2003) diz com preocupação em um de seus artigos, que por vezes, a EA é usada como reprodução de um viés mais conservador, pois ao analisar o tema coleta seletiva, as escolas partem do pressuposto de que o lixo é sempre o principal problema, incentivando uma EA voltada para a reciclagem, esquecendo a relação produção-consumo-cultura. Segundo o autor (2003, p. 2), essas atitudes,

[...] premiam a instituição ou o aluno pelo volume coletado e encaminhado às empresas de reciclagem, mas não abordam quais são os maiores beneficiários desde processo, nem a lógica do consumismo/produtivismo e do supérfluo, ou mesmo as percepções e simbolismos presentes no tema lixo.

A pesquisa EA10, ao analisar o LD de Ciências relacionado à temática ambiental remete ao conservacionismo, pois: "[...] os temas ambientais educativos contidos nele não foram incorporados ao teor dos assuntos da disciplina de Ciências, sendo abordados, de maneira geral, como contextualizações, exemplos ou assuntos complementares à disciplina em seções adicionais ao conteúdo" (p. 186). Já a pesquisa EA2 mostrou que, "[...] muitos Livros Didáticos em relação a temática ambiental não utilizam os textos como um meio para se atingirem os fatos, mas para se saber o conteúdo enquanto um fim em si mesmo" (p. 16).

Com relação à $E A$, é importante afirmar que, em muitos casos, os LD confundem o seu papel. Martins e Guimarães (2002) já citavam em suas pesquisas que o LD se limita a oferecer informações sobre o meio ambiente, trazendo temas como fauna, flora, biodiversidade, desmatamento e/ou lixo, por exemplo. Esses temas são de suma importância, no entanto, falta agregar os valores humanos para que se tenha a mudança desejada: sensibilização, 
percepção e realmente uma mudança de postura perante as questões ambientais.

A pesquisa EA5, se observou que o uso dos materiais didáticos depende, muitas vezes, da ação e postura dos professores para inserir na discussão escolar, temas ambientais na sala de aula, pois; "Não há um objetivo concreto, por parte do estado e dos livros didáticos, de transformar as condições de opressão social e de degradação ambiental. [...] Desse modo, em sua materialidade atual, o potencial dos livros didáticos enquanto um instrumento de Educação Ambiental crítica se limita a inserção do tema em sala de aula, devendo ser aprofundado e aprimorado pelas educadoras e pelos educadores" (EA5, p. 8).

Desse modo, o estudo nos mostrou que a EA na maioria das pesquisas acadêmicas chegou à conclusão de que não é trabalhado a contento nos materiais didáticos, o que prejudica o estímulo dos alunos para pensar o meio ambiente de forma crítica ou desenvolver atividades que visem à transformação social. Muitos materiais não abordam questões ambientais diretamente, deixando a desejar nas ações que poderiam estimular 0 desenvolvimento sustentável.

Nesse aspecto, as pesquisas EA1, EA2, EA3, EA4, EA5, EA6, EA7, EA8, EA10, EA12, EA13 e EA14 foram caracterizadas na concepção Conservacionismo, nos dando a impressão de que a inserção da $E A$ dependerá muito, na maioria das vezes, da capacitação dos profissionais da educação para se constituir foco de transformação política, cultural, econômica e social.

Um estudo realizado por Goergen (2005) aponta que, embora os educadores se digam comprometidos com a ética e os valores sociais e ambientais frente às ações educativas, analisando a estrutura e o cotidiano escolar, constata-se que a ética tem um valor muito restrito na escola. Para muitos autores (MORIN, 2001; GRÜN, 1994) isso é resultado do paradigma reducionista da ciência moderna, que gerou a distinção entre fatos e valores, ciência e ética, privilegiando os fatos e a ciência, desprezando os demais aspectos. O que requer repensarmos a questão de fragmentação, mas também dos valores sociais e éticos intrínsecos.

Neste sentido, as pesquisas EA9 e EA11 com potencial de EA crítica e reflexiva, estão caracterizadas com a concepção Ecologia Social. Essa concepção: "[...] diferencia-se primordialmente, por apresentar um conceito de meio ambiente baseado nas relações dinâmicas entre os aspectos naturais e sociais" (MELLO; TRIVELATO, 1999, p. 9).

A pesquisa EA9 objetivou analisar como a temática água é abordada nas práticas educativas, verificando-se a concepção da Ecologia Social, pois foram encontrados em seus resultados, projetos especiais a respeito da EA em dez escolas. Esses projetos tratam sobre a EA de forma geral. Assim, as, "[...] práticas educativas são baseadas em aulas expositivas, leitura de textos 
informativos ou contidos nos livros didáticos, pesquisas e experimentos físicoquímicos. Os docentes consideram relevante ensinar sobre a água e destacam principalmente os hábitos e atitudes em prol do seu uso racional na escola e nas residências" (p. 8).

Desse modo, percebemos que as atividades propostas, apesar de merecerem aprofundamentos teóricos, estimulam os alunos a pensar de forma crítica e reflexiva sobre as temáticas ambientais. Dessa forma, entendemos a importância de se analisar os LD, pois são materiais didáticos que tem potencial para levar o pensamento crítico e reflexivo aos alunos. $O$ trabalho EA11 enfatiza que: "O livro didático é a principal ferramenta de apoio didático utilizada pelo professor e, portanto fundamental para o processo de ensino aprendizagem. Convém, pois, que o mesmo aborde conteúdos de aprendizagem promovendo a construção de conhecimentos de forma reflexiva, metacognitiva" (p. 9).

Segundo os resultados da pesquisa EA11, foi proposta uma autoavaliação do aluno sobre temas referentes a questões ambientais, favorecendo a construção de uma visão crítica e reflexiva do aluno. Desse modo, o trabalho em questão conclui que os LD precisam estar de acordo com a proposta de fazer o aluno refletir usando seus conhecimentos de forma autônoma, crítica e responsável. Nesse sentido e segundo Schulz et al. (2012, p. 10),

[...] a EA então pode ser considerada uma ferramenta eficaz de proteção ao meio ambiente, de prevenção a problemas futuros, de busca de soluções e alternativas para os problemas já estabelecidos, à medida que integra e envolve a todos nesse processo, não mais apenas como meros espectadores, mas como agentes de transformação.

Desse modo, percebemos a importância de levar em consideração o que os estudantes têm para dizer como parte do trabalho em sala de aula. Nesse sentido, o currículo escolar precisa desenvolver a capacidade de pensar dos estudantes, e não apenas solucionar problemas sociais/ambientais pontuais (UHMANN; ZANON, 2012). Nesse sentido, o espaço escolar torna-se um lugar estratégico que precisa transformar o comportamento dos educandos, desde o ensino fundamental até a universidade, afim de, provocar mudanças enriquecendo o aprendizado dos jovens (GONÇALVES, 2019).

\section{Conclusão}

Após a análise das pesquisas acadêmicas (teses e dissertações) constatamos o predomínio da concepção Conservacionismo, esta que se preocupa em destacar os impactos ambientais, pois não estimula ações de transformação social. Dentre as quatorze pesquisas selecionadas, apenas duas tiveram resultados satisfatórios em relação à $E A$, ou seja, os materiais 
didáticos visam uma postura mais crítica em relação a temática ambiental, inclinando-se para a Ecologia Social.

Megid Neto e Fracalanza já em 2003 apontavam que os LD trabalhavam as questões ambientais, "[...] de forma fragmentada, estática, antropocêntrica $e$ sem localização espaço-temporal (2003, p.151)." Dessa maneira, o aluno permanece passivo, depositário de informações e desconexo em relação à contextualização da realidade, aqui em especial da EA.

A EA precisa ser vista e construída por meio do diálogo, reflexão, experiências individuais e coletivas, mesmo sabendo que: "trabalhar na perspectiva da EA crítica ainda é um desafio, tendo em vista a complexidade das diferentes concepções e práticas existentes (também limitadas na sua efetivação)" (UHMANN; VORPAGEL, 2018, p.2).

Dessa forma, ao analisarmos as pesquisas foi possível constatar que isso não está acontecendo, ou se está, ainda ocorre de forma parcial. Os resultados mostram a necessidade de mais questionamento e debates, ou mesmo o incentivo na participação de movimentos socais e políticos que visem à sustentabilidade. Além dos aprendizados sobre a questão dos problemas ambientais, é preciso compreender a importância de reduzirmos o consumo induzido. É preciso, segundo Carvalho (2004), superar a dicotomia entre natureza e sociedade para que haja relações de interação permanente entre a vida humana social e a vida biológica da natureza.

Diante destes argumentos, a escola se torna um ambiente imprescindível para enfatizarmos a EA. Para isso, é necessária uma gestão democrática com um currículo que aborde a EA de forma crítica, integrada e reflexiva com um espaço físico saudável. O que torna a escola um lugar aliado aos propósitos de potencializar ações voltadas à questão socioambiental.

\section{Referências}

AMARAL, I. A. Os fundamentos do ensino de Ciências e o livro didático. In: FRACALANZA, H.; MEGID NETO, J. (Orgs.). O livro didático de Ciências no Brasil. Campinas: Komedi, 2006. p. 83-123.

CARVALHO, L. M. et al. Enfoque pedagógico: conceitos, valores e participação política. In: TRAJBER, R.; MANZOCHI, L. H. (Orgs.). Avaliando a Educação Ambiental no Brasil: materiais impressos. São Paulo: Gaia, 1996. p. 77-119.

CARVALHO, I. C. M. Educação Ambiental: a formação do sujeito ecológico. São Paulo: Cortez, 2004.

FRACALANZA, D. C. Crise ambiental e ensino de ecologia: o conflito na relação homem-mundo natural. Tese de Doutorado. Campinas, São Paulo, 1992. Disponível em: <http://bdtd.ibict.br/vufind/Record/CAMP 690f6639b6 9f3b323694525f41c2c1f7>Acesso em: 01 nov. 2019. 
GOERGEN, P. Educação e valores no mundo contemporâneo. Educação e Sociedade, Campinas, v. 26, n. 92, p. 983-1011, 2005.

GONÇALVES, T. M. O trabalho interdisciplinar em Educação Ambiental: reflexão sobre a prática docente. Revista Brasileira de Educação Ambiental, v. 14, no3, p. 41-49, 2019.

GRÜN, M. Uma discussão sobre valores éticos em Educação Ambiental. Educação e Realidade, Campinas, v. 19, n. 2, p. 171-195, 1994.

GRÜN, M. Ética e Educação Ambiental: a conexão necessária. Campinas: Papirus, 2001.

GÜLLICH, R. I. C. Didática das ciências. 1를 Edição, Curitiba, 2013.

LAGO, A.; PÁDUA, J. A. O que é Ecologia. $8^{a}$ ed. São Paulo: Brasiliense, 1992.

LAJOLO, M. Livro didático: um (quase) manual de usuário. Brasília, v. 16, n. 69, p. 3-7, 1996.

LEFF, E. Epistemologia ambiental. São Paulo:Cortez, 2001.

LEIS, H. R.; D'AMATO, J. L. O ambientalismo como movimento vital: análise de suas dimensões histórica, ética e vivencial. In: CAVALCANTI, C. (Org.). Desenvolvimento e natureza: estudos para uma sociedade sustentável. São Paulo: Cortez; Recife: Fundação Joaquim Nabuco, 1995. p. 77-103.

LOUREIRO, C. F. B. Sustentabilidade e Educação: um olhar da ecologia política. São Paulo, Cortez, 2012.

LOUREIRO, C. F. B. Premissas teóricas para uma Educação Ambiental transformadora. Revista Ambiente e Educação, v. 8, p. 37-54, 2003.

LOUREIRO, C. F. B. Teoria social e questão ambiental: pressupostos para uma práxis crítica em Educação Ambiental. In: LOUREIRO, C.F.B.; LAYRARGUES, P. P.; CASTRO, R. S. C. (Orgs.). Sociedade e meio ambiente: a Educação Ambiental em debate. São Paulo: Cortez, 2000. p. 13-51.

LUDKE, M.; ANDRÉ, M. E. D. A. Pesquisa em educação: abordagens qualitativas. São Paulo: EPU, 1986.

MARPICA, N. S.; LOGAREZZI, A. J. M. Um panorama das pesquisas sobre Livro Didático e Educação Ambiental. Ciência \& Educação, v. 16, n. 1, p. 115130, 2010.

MARTINS, E. de F.; GUIMARÃES, G. M. A. As concepções de natureza nos livros didáticos de ciências. Ensaio - Pesquisa em Educação em Ciências. V4, n.4, dez., 2002.

MEGID NETO, J.; FRACALANZA, H. O livro didático de ciências: problemas e soluções. Ciência \& Educação, v. 9, n. 2, p. 147-157, 2003. 
MELLO, C. M; TRIVELATO, S. L. F. Concepções em Educação Ambiental. Anais do II Encontro Nacional de Pesquisa em Educação em Ciências. São Paulo, 1999.

MORIN, E. Os sete saberes necessários à educação do futuro. São Paulo: Cortez, Brasília: Unesco, 2001.

SANTOS, L. F. A. dos. Apostila Metodologia da Pesquisa Científica II. Faculdade Metodista de Itapeva, 2006.

SCHULZ, M. S. et al. Educação Ambiental na educação básica e superior segundo licenciandos de ciências biológicas e professores em exercício. Rev. Eletrônica Mestr. Educ. Ambient. v. 29, julho a dezembro de 2012.

SORRENTINO, M. Educação Ambiental e Universidade: um estudo de caso. São Paulo, 1995. Tese (doutorado em Educação) - FEUSP, São Paulo. Disponível em: https://bdpi.usp.br/item/000742327. Acesso em: 02 de nov. de 2019.

UHMANN, R. I. M. Interações e Estratégias de Ensino de Ciências com foco na Educação Ambiental. Curitiba: Appris, 2013.

UHMANN, R. I. M. VORPAGEL, F. S. Educação Ambiental em foco no ensino básico. Pesquisa em Educação Ambiental, v. 13, n.2, São Paulo, 2018.

UHMANN, R. I. M; ZANON, L. B. Ações pedagógicas no ensino de física com foco na Educação Ambiental. Rev. Eletrônica Mestr. Educ. Ambient. v. 29, julho a dezembro de 2012.

\section{Referências investigadas}

(EA9) ANANIAS, N. T. Educação Ambiental e água: concepções e práticas educativas em escolas municipais. Dissertação de Mestrado. Universidade Estadual Paulista, Programa de Pós Graduação em Educação, Faculdade de Ciências e Tecnologia. Presidente Prudente, 2012. Disponível em: https://repositorio.unesp.br/bitstream/handle/11449/92242/ananias nt me prud .pdf?sequence $=1$ \&isAllowed=y. Acesso em: 05 de maio de 2019.

(EA7) BARBOSA JUNIOR, I. R. Meio ambiente e ética: entrecruzando olhares no ensino de ciências. Dissertação de Mestrado. Universidade Federal do Pará, Instituto de Educação Matemática e Científica, Programa de Pós Graduação em Ciências e Matemática, Belém, 2010. Disponível em: http://repositorio.ufpa.br/jspui/handle/2011/2667. Acesso: 05 de maio de 2019.

(EA3) BLACHECHEN, B. M. Abordagem ambiental em livros didáticos de ciências de 1ํ a 8o série em 1983 e 2008: um estudo comparativo. Dissertação de Mestrado, Universidade Regional de Blumenau, Programa de Pós Graduação em Educação, Mestrado em Educação. Blumenau, 2008. Disponível:http://bdtd.ibict.br/vufind/Record/FURB 938a19710ebb7d0bb508344 2c91d48c5. Acesso em: 05 de maio de 2019. 
(EA6) CARVALHO, M. L. O de S. A abordagem das questões ambientais como forma de inserção da Educação Ambiental no ensino de ciências. Dissertação de Mestrado. Universidade Federal de Minas Gerais, Faculdade de Educação, Programa de Pós-Graduação em Educação: Conhecimento e Inclusão Social. Belo Horizonte, 2010. Disponível em: https://repositorio.ufmg.br/handle/1843/BUOS-8GZNQ5. Acesso em: 05 de maio de 2019.

(EA2) GROSSI, F. de M. C. Educação Ambiental e o Livro Didático no ensino fundamental. Dissertação de Mestrado. Universidade Federal de Viçosa, Programa de Pós Gradação em Extensão Rural. Viçosa, 2008. Disponível em: https://www.locus.ufv.br/handle/123456789/9941. Acesso em: 05 de maio de 2019.

(EA10) GUIMARÃES, Z. F. S. A Cigarra e a Formiga: a Educação Ambiental e o ensino de ciências em escolas públicas de Brasília, Distrito Federal. Tese de Doutorado, Universidade de Brasília, Faculdade de Educação, Programa de Pós Graduação em Educação. Brasília, 2012. Disponível em: https://repositorio.unb.br/handle/10482/12377. Acesso em: 05 de maio de 2019.

(EA5) MARPICA, N. S. As questões ambientais nos livros didáticos de diferentes disciplinas da quinta série do ensino fundamental. Dissertação de Mestrado. Universidade Federal de São Carlos, Centro de Educação e Ciencias Humanas, Pós Graduação em Educação. São Carlos, 2008. Disponível

em:https://repositorio.ufscar.br/bitstream/handle/ufscar/2469/2077.pdf?sequenc $\mathrm{e}=1$. Acesso em: 05 de maio de 2019.

(EA14) ONDER, A. D. Educação Ambiental e resíduos sólidos: um estudo nas escolas públicas municipais de São Paulo. Dissertação de Mestrado. Universidade de São Paulo, Programa de Pós Graduação em Sustentabilidade. São Paulo, $2018 . \quad$ Disponível em: https://www.teses.usp.br/teses/disponiveis/100/100136/tde-09042018095938/pt-br.php. Acesso em: 05 de maio de 2019.

(EA4) OTALARA, A. P. O tema água em livros didáticos de ciências de primeira a quarta série do ensino fundamental. Dissertação de Mestrado. Universidade Estadual Paulista, Programa de Pós Graduação em Educação. Rio Claro, 2008 Disponível em: http://bdtd.ibict.br/vufind/Record/UNSP 1ca25a565457355663157a7a31b0fb63 . Acesso em: 05 de maio de 2019.

(EA12) PANDINI, J. C. A prática da Educação Ambiental: caso da unidade de ensino Lígia Chaves Cabral no município de Louro Müller/SC. Dissertação de Mestrado. Universidade do Extrema Sul Catarinense, Programa de Pós Graduação em Ciências Ambientais, Mestrado em Ciências Ambientais. Criciúma, 2016.2 Disponível em: http://repositorio.unesc.net/bitstream/1/5298/1/JAQUELINE\%20CRISTIANE\%2 OPANDINI.pdf. Acesso em: 05 de maio de 2019. 
(EA1) PEGORARO, J. L. Educação Ambiental: a temática da flora, da fauna e dos ambientes naturais (expressões da biodiversidade) a partir da educação formal. Dissertação de Mestrado. Universidade de São Paulo, Escola Superior de Agricultura. Piracicaba, $1998 . \quad$ Disponível em: https://teses.usp.br/teses/disponiveis/11/11142/tde-20181127-161623/en.php. Acesso em: 05 de maio de 2019.

(EA13) RUMENOS, N. N. O tema mudanças climáticas nos livros didáticos de ciências da natureza para o ensino fundamental II: um estudo a partir do PNLD 2014. Dissertação de Mestrado. Universidade Estadual Paulista "Júlio de Mesquita Filho”, Programa de Pós Graduação em Educação. Rio Claro, 2016. Disponível em: https://repositorio.unesp.br/handle/11449/144536. Acesso em: 05 de maio de 2019.

(EA11) SILVA, L. M. da. A Metacognição no Livro Didático de Ciências: um olhar sobre a abordagem ambiental do conteúdo. Dissertação de Mestrado. Universidade Federal Rural de Pernambuco, Programa de Pós Graduação em Ensino de Ciências, Departamento de Educação. Recife, 2016. Disponível em: http://www.tede2.ufrpe.br:8080/tede2/bitstream/tede2/7450/2/Lidianne\%20Mari a\%20da\%20Silva.pdf. Acesso em: 05 de maio de 2019.

(EA8) VOICHICOSKI, M. S. R. As abordagens do tema meio ambiente pelos livros didáticos e professores da quinta série do ensino fundamental. Dissertação de Mestrado. Universidade Estadual de Ponta Grossa, Programa de Pós Graduação - Mestrado em Educação. Ponta Grossa, 2011. Disponível em:https://tede2.uepg.br/jspui/bitstream/prefix/1320/1/MARCIA\%20SILVANA\% 20RODRIGUES\%20VOICHICOSKI.pdf. Acesso em: 05 de maio de 2019. 